\title{
Exploration on Instructing Mode of the Curriculum - Mechanical Engineering Materials
}

\author{
Yinan $\mathrm{Li}^{\mathrm{a},{ }^{*}, \text { Zilong Peng }}{ }^{\mathrm{b}}$ \\ College of mechanical engineering, Qingdao Technological University, Qingdao 266000, China \\ aliyinan2004@163.com, bpzlmail@163.com
}

\begin{abstract}
In this paper, the new attempts on instructing mode of 'mechanical engineering Materials are conducted in order to improve the students' enthusiasm of learning and encourage the teachers' positivity of teaching. And these new trials are included Moocs, VR technology and project instructing mode, which facilitate the students to master the main content of this curriculum dramatically and improve the teaching quality to a large extent.
\end{abstract}

Keywords: Instructing mode, Moocs, VR technology, project discussion teaching mode.

\section{Introduction}

Mechanical Engineering Materials are one of the compulsory professional basic curriculums for the machinery major. And the main teaching task of this curriculum is to elaborate the basic theory of the mechanical engineering materials from the perspective of the application of mechanical engineering and make the students familiar with the connection among the component of the mechanical engineering materials, the processing technology, the structure and the mechanical properties, and then master the basic principles on how to select and use different kinds of mechanical engineering materials. Through the studying this curriculum, on the basis of mastering the basic theory and knowledge of engineering materials, the students should be acquired the initial ability of selecting the type of metals for the certain machine parts and laying down the procedure of processing techniques of the machine parts. From the perspective of students majored in mechanical engineering, they will mainly work in designing and producing mechanical products. And reasonable selection of metals for these machine parts is one of most important steps in designing and producing mechanical products. Especially as the material science and technology developed by leaps and bounds nowadays, the reasonable selection and application of the new engineering materials is becoming the major measure of improving the quality of products, reducing the cost and developing the new products. Therefore, it is no exaggeration to say that the curriculum- Mechanical Engineering Materials plays a vital role in the whole course system for the students majored in mechanical engineering.

In our department, there are 32 class hours in Mechanical Engineering Materials, including 26 theoretical class hours and 6 experimental class hours. The main instructing contents in classroom embrace the structure and performance of materials, the control of structure and mechanical performance, metals, high polymer materials, ceramic materials, composite materials, the failure and principle of selecting materials, the selection of typical machinery parts and processing procedure and the application of engineering materials. The teaching contents in laboratory embrace the metallographic specimen preparation, the hardness test and observation of equilibrium microstructure of Fe-C phase diagram. From these instructing contents, it can be seen that the arrangement of this curriculum is appropriate and the range of knowledge covers almost all of the materials science. However, there are some shortages during the instructing course. For instance, the given class hours are limited that hardly accomplish the instruction of all knowledge point thoroughly, the amount of experiments is not enough and the experimental apparatus are outdated. Therefore, according to the existing condition of running school and experimental apparatus, we focus on reformation of the instructing mode and take the corresponding measurements to sustain the teaching quality.

In this paper, three reform attempts are conducted and the relationship of these three reform measure is listed in Fig.1. 


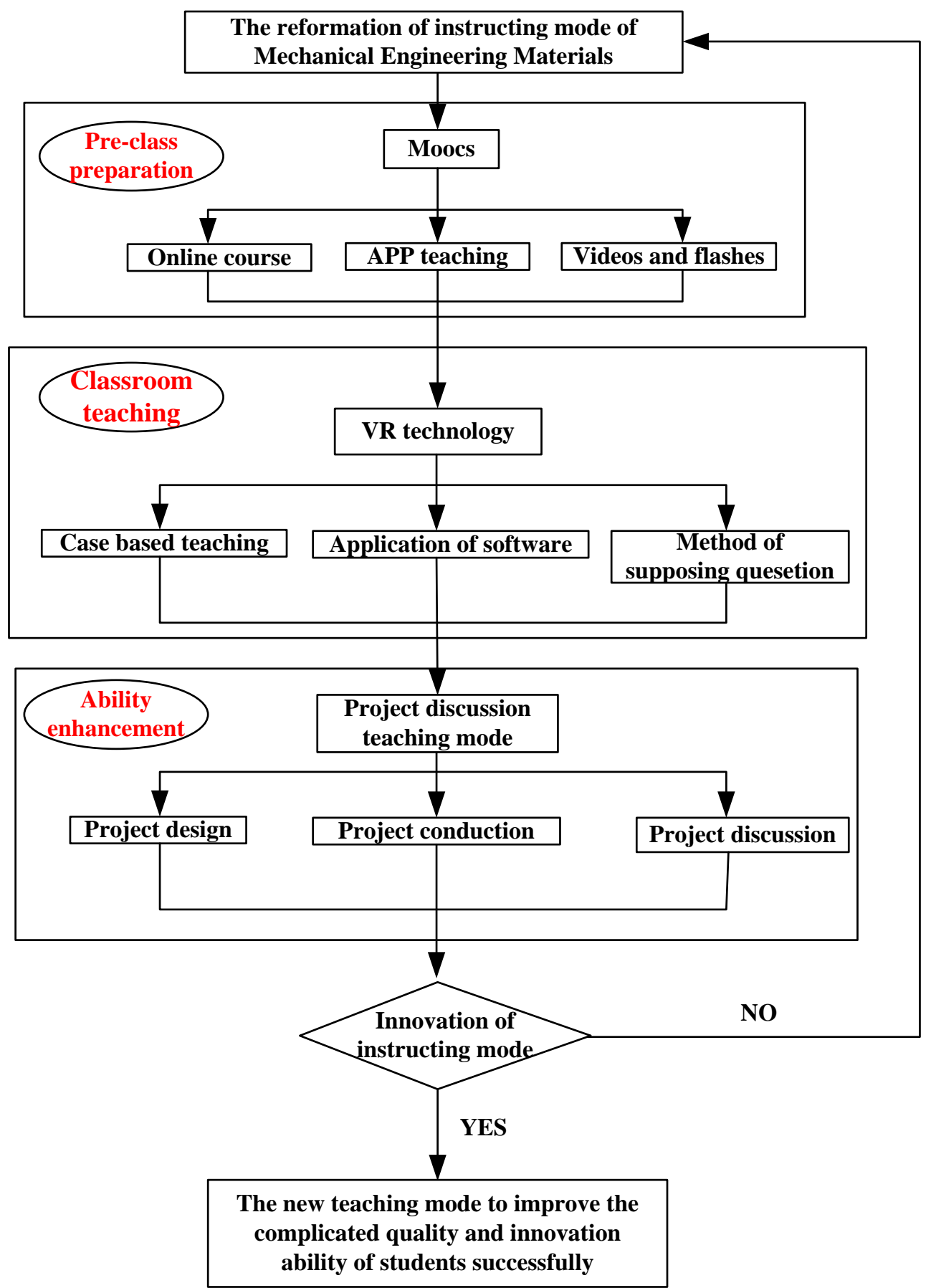

Fig. 1 Schematic diagram of instructing mode of Mechanical Engineering Materials

\section{Reformation on Pre-class preparation}

With the development of computer science and technology, the instructing mode is experiencing the constant developing and updating. And many new methods such as Moocs (massive open on line course) and APP in smartphones had been used in teaching different domain of subjects. In traditional Compared with the traditional teaching mode the Moocs and APP teaching has its special superiorities. Moocs means the online course instruction based on the theory of connectionism and Web-based learning, that is, Moocs is the large scale online open courses, which aim at enhancing the broadcast and sharing of knowledge. The teacher should pinpoint the knowledge points that will be taught in next class. And through the Moocs the students can use the Internet platform to do pre-classroom preparation.

In the traditional teaching method, the teacher only teaches according to the text books, which cannot inspirit the learning interests of the student. And it is hard for students to concentrate in the 
classroom, which cannot guarantee the learning efficiency. Specifically, Mechanical Engineering Materials has the characteristic of boredom and unintelligibility. Once the class teaching effects in one class are not well, it is difficult for the students to catch up with the following learning progress. Then the only thing the students have to do is rote learning, and it is not hard to imagine that the learning effect is definitely poor. If Moocs and APP teaching in smartphone are introduced into the teaching and learning course, the contents of this curriculum become more direct specific vivid and imaginable, which can intrigue the learning interest of the students, transfer the subjective initiatives and arouse the enthusiasm of studying. What's more, it is easier for the teachers to instruct the content clearly and for students to comprehend and master the knowledge. In this way, a virtuous circle between teaching and learning is formed. For instance, our school does not have the heating processing equipment. With the aid of videos and flashes in Moocs, the teacher elaborates the heating processing technology clearly. Meanwhile, some advanced manufacturing technologies such as vacuum heating processing are teaching, which makes the teaching content more comprehensive.

\section{Reformation on classroom teaching}

In the traditional teaching in classroom it is found that the teaching effects are not satisfied, that is, there are about $30 \%$ of the students can master all of the knowledge points that are instructed in the classroom on the premise of pre-class preparation, $50 \%$ of the students only master part of the knowledge points in the classroom teaching, and $20 \%$ of the students cannot comprehend and master the knowledge points due to the poor learning ability and knowledge system in their minds. Therefore it is vital to promote the learning efficiency in the classroom and it is necessary to reform the teaching mode in the classroom.

VR (visual reality) technology is one of the most efficiency methods to enhance the teaching effect. VR technology aims at utilizing visualization technology and Internet technology in order to build and simulate the products during the designing manufacturing producing and testing course. Using VR technology, before the production, all of the details of manufacturing a machinery parts are foresighted, which can ensure the validity of the design and the feasibility of processing. In the course of class teaching, it is found that with the introduction of VR technology the students have the chance to grasp the practical engineering software, which intrigue their learning enthusiasm and then the teaching quality is promoted. For example, a software named DEFORM is adopted in teaching Mechanical Engineering Materials. DEFORM is a kind of processing simulation system based on finite element method, the main function of which is analyzing the feasibility of metal forming and corresponding heating processing procedure. Through the simulation of the whole manufacturing course, the engineers and design faculties can explicit the key points of design and manufacture, cut down the producing cost and raise the efficiency of design and shorten the developing circle of new products. With this software, a project case can be illustrated for application of engineering materials. For instance, when teaching Mechanical Engineering Materials, the teacher can take the simulation model for heating process of gear for a case study. Through the dynamic illustration from the simulation results, the basic theory about heating process can be expressed directly and the students are likely to absorb the knowledge. At the same time, the students are curious about in the region and promote the learning activity. By using the VR technology, some difficult problems have been settle down, relieved the contradiction between the teaching and the learning, broaden the imagination gap of the students and promote the innovation ability of them.

\section{Reformation on ability enhancement}

The project discussion teaching mode is one of most efficient methods to improve the complicated capacities of the students. The project teaching discussion method is a student-oriented interactive teaching method, which emphasizes on cultivating the practice ability of student when facing the actual engineering problems. There are four steps in project teaching mode, which are imitation, practice, enhancement and innovation. And the last three parts are the main contents of the project discussion 
teaching mode. In other words, the teacher need to provide specific case that exists in the actual manufacturing process, and the students need to find the resolution, set out the procedure and form a proper and validate project on the basis of the existing knowledge system they have. During the implementing course of the project, the discussion or brain storm among the students is essential as the student can learn the knowledge, enhance the innovative ability as well as cultivate the practical ability.

In the curriculum- Mechanical Engineering Materials, the synthesis module are established to improve the complicate qualities and innovation ability of the students. Taking the selection metal for specific machinery part for example, the students are divided into several studying group, and each group embraces 5-6 students and are given a specific machinery part such as gears, axis or tools. The study group should work together to finish all the steps of selecting work and conduct the corresponding heating process procedure. They also need to form a completed and detailed report and then put the emphasis into PPT. The representatives of each group will do a presentation in the class and the students in other groups and teacher have the chance to study and discussion the pros and cons of the project. Through the project discussion teaching mode, the students can master the knowledge in a broaden vision as well as improve the complicated abilities.

\section{Summary}

Through the new attempts of teaching mode of curriculum- Mechanical Engineering Material, the learning enthusiasms of the students are arouse and the studying efficiency is promoted. Through the application of Moocs, VR technology and project discussion teaching mode, the learning and innovation ability of the students are enhanced markedly.

\section{Acknowledgements}

This work was supported by the Project of Shandong Province Elite University Construction (MX4-020, MX4-053).

\section{References}

[1] X. Z. Xu. Research on teaching material construction of "Electrical Engineering and Electronics" based on outstanding engineers plan The International Conference on Biotechnology, griculture, Environment and Energy. 2014.244-247.

[2] C. Yang. Z. Li. A Tentative Exploration of the Educational Training Mechanism of Outstanding Engineers' Mineral Processing Engineering Major. 2015 International Conference on Social Science,Education Management and Sports Education. 2015.79-82.

[3] H. Chen, Z. H. Tan. Discussion on "Outstanding Engineers" Training Program for Information Security Major in China. The 2012 International Conference on Future Computer Supported Education. 2012:877-881.

[4] P. H. Zhu, J.Y. Wu. On Practice Teaching System of "A Plan for Educating and Training Outstanding Civil Engineers". 2013 2nd International Conference on Education Reform and Management Innovation. 2013:226-229.

[5] S.X. Wang, G.S. Liu. Course Teaching Design for Mechanical Engineering Materials under the Outcome-based Education Theory. 2014 4th International Conference on Applied Social Science. 2014:301-307.

[6] M.Q. Xue. Application of Multimedia Technology in Mechanical Engineering Material Teaching of Vocational College. 2011 International Conference on Frontiers in Computer Education. 2011:26-30. 